\title{
Clinical characterstics, precipitating factors and glycemic control among diabetic ketoacidosis patients admitted to university hopsital in Northwest Ethiopia: A hospital based observational study.
}

Gizework Mekonnen Alemnew ( $\nabla$ gizeworkalemnew@gmail.com )

University of Gondar College of Medicine and Health Sciences

Tadesse Melaku Abegaz

University of South Australia

Research article

Keywords: Clinical characterstics, diabetic ketoacidosis, Ethiopia, glycemic control, precipitating factors

Posted Date: December 10th, 2019

DOI: https://doi.org/10.21203/rs.2.18079/v1

License: (c) (1) This work is licensed under a Creative Commons Attribution 4.0 International License.

Read Full License 


\section{Abstract}

Aims: The aim of the study was to determine the clinical characteristics, precipitating factors and the level of glycemic control of diabetic ketoacidosis patients admitted to Debretabor General Hospital, northwest Ethiopia.

Methods: A retrospective, cross-sectional study was conducted at Debretabor General Hospital and data was collected from June 1 to 30, 2018.Participants included in the study were all diabetic patients with diabetic ketoacidosis admitted to the General Hospital during the study period. The primary outcome was to determine precipitating factors for DKA and the level of glycemic control of diabetic ketoacidosis patients. All the statistical data was carried out using Statistical Package for Social Sciences (SPSS).

Result: A total of 387 patients' medical records contained pertinent complete information included in this study. The mean age of the patients was $33.30 \pm 14.96$ years. The majority of patients were females 244 (63.0\%). The most common clinical presentation was polyuria and polydipsia in ( $n=379,97.9 \%)$ of patients. The most common precipitating factor was newly diagnosed diabetics mellitus $150(38.8 \%)$. Binary logistic regression showed that for every increase in the duration of the disease(DM) by 1 year, the likelihood of controlling hyperglycemia would increases nearly 1.5 times AOR:1.497 [1.203-1.814].

Conclusions: In this study, newly onset type 1 diabetes mellitus was the major precipitating factor for DKA. Polyuria and polydipsia were the most common presenting clinical characteristic of diabetic ketoacidosis. Long standing DM was found to be associated with good glycemic control among DKA patients.

\section{Introduction}

Diabetic ketoacidosis (DKA) represent a constellation of hyperglycemia, ketone bodies and metabolic acidosis in diabetic patients. A systematic review of literatures reported that the epidemiology of DKA has not been clearly elucidated among diabetes Mellitus (DM) patients. Once, patients are diagnosed with DM, they usually are placed on medications including hypoglycemic agent and insulin based on the level of glycemic control(1). Physical activities have been regularly recognized to optimize the level of glucose and hyperlipidemia which coexists commonly in DM patients(2). Despite continuous efforts to get control of DM and its complications, however, the achievement of an ideal glucose level is not always possible(3). Some patients face difficulties of keeping the glucose level up to the recommended point. Hyperglycemic episodes are one of the manifestations of abnormal or inadequate control of glucose in the body. When DM patients fail to attain appropriate level of glucose in the body, they encounter a triad of hyperglycemia, metabolic acidosis and production of ketone bodies which leads to the diagnosis of DKA(4). Often times, hyperglycemia is accompanied by the production of ketone bodies since the glucose is not effectively utilized by the body in spite of surplus state in the serum. The ketone bodies results in the disturbance of body acid-base balance and osmolality of the body fluid gives rise to metabolic acidosis(5). 
Different factors have been reported as the Precipitating factors (PFs) for DKA. Infection has been found to be one of the leading precipitants of DKA in most studies $(6,7)$. An observational study conducted at a tertiary care center in Andhra indicated that infection was found to be the first leading cause of DKA, accounting for $43 \%$ cases. Among the infections, urinary tract infections were most common, followed by septicemia and pneumonia(8). In another hospital based descriptive study done in tertiary care hospital of Eastern Nepal, infection was the most common precipitating factor (56.25\%) (9). A three year retrospective study done in Jimma in 2013 indicated that the most common precipitants of DKA were infections $59 \%$, and non-compliance to antidiabetic medications $32.3 \%(10)$. On the contrary a prospective cross-sectional study done in Kenyatta National Hospital, Nairobi amongst the precipitating factors, missed doses had the major precipitating factor of KDA(11). Further, retrospective observational cohort study done in Saudi Arabia showed that missing /non-compliance of insulin dose caused 54.2\% of DKA (12), cross-sectional study Benghazi-Libya (2007)(13). other studies done in New Zealand (14), Brazil (15), and Israel reported the same precipitating for DKA(16). First presentation of DM has also been identified as a significant PF among type 1 DM patients (17). A retrospective study done in Jimma University Specialized Hospital in 2013 showed that a newly diagnosed diabetes contributed $23.6 \%$ of $\operatorname{DKA}(10)$.

The constellation of PFs make the glucose level rise and get the way for DKA to develop subsequently which on the other hand increase the prevalence of DKA in Ethiopia exponentially. However, emphasis has not been given to determine the most pertinent PFs since the down of time. Estimation of PFS in the context of developing country would help to direct interventions or strategies to reduce these factors and the occurrence of DKA. In light of this, the present studyaimed to determine the precipitating factors for diabetic ketoacidosis among diabetic patients admitted to Debretabor General Hospital (DGH) in northwest Ethiopia.

\section{Methods}

\subsection{Study setting, design and period}

A retrospective cross-sectional study was conducted at Debretabor General Hospital from June 1 to 30, 2018. Debre Tabor General Hospital is a government hospital found in Debre Tabor Town, South Gondar Zone of Amhara Regional state which is 667 kilometers far from Addis Ababa, the capital city of Ethiopia in Northwest direction and 102 kilometers far from Bahir Dar town. The hospital diabetic clinic gives a twice weekly outpatient service for DM patients. Based on patient fasting blood glucose level antidiabetic medication(s) dose adjustment and regimen change is made routinely.

\subsection{Population}

All DM patients with DKA who were admitted to inpatient ward of DGH from August 1, 2010 to May 31, 2018 were our study population. Participants included in the study were all diabetic patients whose 


\subsection{Sample Size determination and sampling technique}

Single population proportion formula was used to calculate the minimum sample size based on the following assumptions: $5 \%$ level of significance (a), $5 \%$ marginal error (d), and 0.5 prevalence of good glycemic control among DKA patients.

$n=Z 2 a 2 p 1-p d 2 n=(1.96) 20.50 .5(0.05) 2=384.16$

Since the total number of diabetic patients attending who developed DKA from August 2010 to May 2018(N)was less than 10,000 (682), the final corrected sample size was 246.

Corrected sample size $=N * n N+n,(682 * 384) /(682+384)=246$,

But, due to easily accessibility of data we included all eligible subjects to attain the final sample size of 387 subjects.

\subsection{Eligibility criteria}

All DKA patients who were admitted to the inpatient ward of DGH and fulfilled the inclusion criteria August 2010 to May 312018 were included.

\subsection{Study variables}

PFs and level of glycemic control were our study variables. Independent variables include: age, gender, residence, type of DM, severity of DKA, admission blood glucose readings, blood pressure, respiratory rate, pulse rate, co morbidities, precipitating factors, frequency of serum glucose rebound, frequency of ketone rebound.

\subsection{Data collection methods}

Medical record of patients with DKA admitted to the hospital was traced from patient logbook and drawn from card room. Selection of medical records for sampling was based on the physician's confirmed diagnosis on patient logbooks. Participants included in the study were all diabetic patients with DKA admitted to $\mathrm{DGH}$ with age $\geq 15$ years old whose medical records contained complete pertinent data. The data was collected by trained data collector using structured and pretested data extraction tool. Data was collected on patient demographics, presenting symptoms, precipitating causes of DKA, vital signs, biochemical profiles (admission blood glucose, admission urine ketone, urine glucose) at presentation to the inpatient department and time from presentation to resolution of urine ketones. 


\subsection{Data Analysis}

All the statistical data was carried out using Statistical Package for Social Sciences (SPSS), version 22 (SPSS Inc., Cary, NC, USA). Descriptive statistics (mean, \%, SD,) was calculated for categorical variables. Binary logistic regression was done to determine the factors that affect the level of glycemic control.

\subsection{Ethics}

The study was conducted after ethical clearance letter received from research and ethics review committee of school of pharmacy, University of Gondar College of medicine and health science, hospital clinical director and head of the medical ward of DGH. Data was collected anonymously.

\subsection{Operational definitions}

$D K A$ is defined as admission blood glucose $>250 \mathrm{mg} / \mathrm{dL}$ and presence of ketonemia and/or ketoneuria (7).

Hyperglycemia is defined as random plasma glucose $>200 \mathrm{mg} / \mathrm{dL}(18)$ and Hypoglycemia is defined as a blood glucose level $\leq 70 \mathrm{mg} / \mathrm{dL}(19)$.

Euglycemia is defined as serum glucose of between 100 and $200 \mathrm{mg} / \mathrm{dl}$ once the patient is hospitalized with $\operatorname{DKA}(7,20)$

Clinical characteristics of DKA include a history of polyuria, polydipsia, weight loss, vomiting, dehydration, weakness, and mental status change.

Glycemic control: defined as poor and good glycemic control according to the incidence of rebound hyperglycemia or hypoglycemic state after admission of the patient due to DKA.

\section{Results}

\subsection{Sociodemographic characteristics of DKA patients}

Out of 387 patients, $305(78.8 \%)$ and 82(21.2\%) patients had type 1 DM and Type 2 DM, respectively. Among them, 244(63.0\%) were females and 143(37.0\%) were males. The female: male ratio was 1.7:1. The mean age of the patients was 33.30 14.96 (range 15-64 years). More than half of the patients 264 $(68.2 \%)$ were urban residents and the remaining $123(31.8 \%)$ were rural residents. Family history of diabetes was reported in only $50(12.9 \%)$ of the patients.

The mean duration of DM was $26.21( \pm 39.62)$ months ranging from newly diagnosed ones to a maximum duration of 192 months. The mean frequency of DKA episodes was 1.5 times, maximum 
frequency of DKA episodes was 8 times and the minimum was once (table 1).

Table 1: Sociodemographic characteristics of DKA patients admitted at DGH from August 2010 to May 31, 2018.

\begin{tabular}{|ll|}
\hline Characteristics & Frequency (\%) \\
\hline Age (mean \pm SD) & $33.29( \pm 14.96)$ \\
\hline Sex & \\
\hline Male & $143(37.00)$ \\
\hline Female & $244(63.00)$ \\
\hline Residence & \\
\hline Urban & $264(68.20)$ \\
\hline Rural & $123(31.80)$ \\
\hline Family history & \\
\hline Yes & $50(12.90)$ \\
\hline No & $53(13.70)$ \\
\hline Unknown & $284(73.40)$ \\
\hline Type of DM & \\
\hline Newly diagnosed type $1 \mathrm{dm}$ & $146(37.70)$ \\
\hline Newly diagnosed type $2 \mathrm{dm}$ & $21(5.40)$ \\
\hline Known type $1 \mathrm{dm}$ & $159(41.10)$ \\
\hline Known type 2 dm & $61(15.80)$ \\
\hline Duration of DM (mean $\pm S D)$ & $26.22( \pm 39.67)$ \\
\hline Mean frequency of DKA episode & $1.50( \pm 1.00)$ \\
\hline 1 time & $272(70.30)$ \\
\hline 2 times & $74(19.10)$ \\
\hline 3 times & $20(5.20)$ \\
\hline$\geq 4$ times & $21(5.50)$ \\
\hline
\end{tabular}

\subsection{Clinical characteristics of DKA patients}


Polyuria and polydipsia (97.9\%) were the most frequent clinical manifestations among patients with DKA followed by easy fatigability (82.9\%) and abdominal pain (47.0\%). The mean pulse rate, systolic blood pressure (SBP), diastolic blood pressure (DBP), respiratory rate(RR) and body temperature at admission were $94.17( \pm 14.54), 104.30( \pm 15.51), 67.84( \pm 10.42), 24.85( \pm 4.30)$ and $36.47( \pm 0.94)$, respectively.

About $276(71.3 \%)$ of patients had normal pulse rate and $108(27.9 \%)$ were tachycardic. About $227(58.7 \%)$, were normotensive and the remaining 73(18.9\%) were stage 1 hypertension. Majority of the patients $224(57.88 \%)$ had $(\nabla+3)$ ketoneuria and the remaining $163(42.11 \%)$ had $(\geq+3)$ ketoneuria at the time of admission in the hospital. On the other hand, $161(41.60 \%)$ patients had urine glucose $(+2)$ and $130(33.60 \%)$ patients were glucose +3 (Table 2).

Table 2: Admission clinical characteristics of DKA patients admitted at DGH from August 2010 to May 31, 2018. 


\begin{tabular}{|c|c|}
\hline Clinical characteristics & Frequency (\%) \\
\hline polyuria +polydipsia & $379(97.90)$ \\
\hline Fatigability & $321(82.90)$ \\
\hline Abdominal pain & $182(47)$ \\
\hline Vomiting & $70(18.10)$ \\
\hline Others & $36(9.3)$ \\
\hline Pulse rate (means) & $94.17( \pm 14.54)$ \\
\hline Normal & $276(71.30 \%)$ \\
\hline Tachycardia & $108(27.90 \%)$ \\
\hline Bradycardia & $3(0.8 \%)$ \\
\hline Temperature $\left({ }^{0} \mathrm{C}\right)$ & $36.47( \pm 0.94)($ range $32.50-39.40)$ \\
\hline Respiratory rate (mean \pm SD) & $24.85( \pm 4.300)$ (range $14-44)$ \\
\hline Respiratory status & Frequency (\%) \\
\hline normal & $261(67.40)$ \\
\hline tachypnea & $126(32.60)$ \\
\hline SBP $($ mean \pm SD $)$ & $104.30( \pm 15.510)($ range $70-180)$ \\
\hline $\mathrm{DBP}($ mean $\pm \mathrm{SD})$ & $67.84( \pm 10.422)($ range $40-110)$ \\
\hline \multicolumn{2}{|l|}{ BP status } \\
\hline hypotension & $46(11.9)$ \\
\hline normal & $227(58.7)$ \\
\hline elevated & 14(3.6) \\
\hline stage 1 & 73(18.9) \\
\hline stage 2 & $27(7.0)$ \\
\hline \multicolumn{2}{|l|}{ Urine Ketone } \\
\hline$\nabla+3$ & $224(57.88)$ \\
\hline$\geq+3$ & $163(42.11)$ \\
\hline \multicolumn{2}{|l|}{ Urine glucose } \\
\hline Urine glucose free & $2(0.50)$ \\
\hline+1 & $22(5.70)$ \\
\hline
\end{tabular}




\begin{tabular}{|ll|}
++2 & $161(41.60)$ \\
\hline+3 & $130(33.60)$ \\
\hline+4 & $33(8.50)$ \\
\hline Not measured & $39(10.10)$ \\
\hline Comorbidity & \\
\hline No & $355(91.70)$ \\
\hline Yes & $32(8.30)$ \\
\hline
\end{tabular}

\subsection{Precipitating factors of DKA}

About 258(66.67\%) of DKA patients had known precipitating factor for DKA. The predominant precipitating factor of DKA was new onset type 1 DM 150(38.8\%) followed by poor compliance to antidiabetic treatment (14.7\%) and infections (13.2\%). About 129 (33.33\%) patients had no known precipitating factor (fig 1). Urinary tract infection was the most common infection $24(47.05 \%)$ that precipitated DKA and respiratory tract infection 21(41.17\%) was the second most infection that precipitate DKA.

\subsection{Severity of DKA and Ketone bodies}

About three-fourth (75.5\%) of the patients was presented with mild DKA, approximately nineteen percent 74(19.1\%) were presented with moderate DKA and the remaining 21 (5.4\%) were severe DKA. Sixty-eight (17.6\%) patients experienced rebound ketoneuria one times and six (1.6\%) patients had rebound ketone two times in their hospital stay. The mean first ketone-free time was $9.23( \pm 10.954)$ hours and last ketone free time was $9.49( \pm 11.05)$ hours (range 1-138) (Table 3).

Table 3: Severity of DKA and ketone bodies in DKA patients. 


\begin{tabular}{|ll|}
\hline Severity of DKA and urine ketone bodies & Frequency (\%) \\
\hline Mild DKA & $292(75.5 \%)$ \\
\hline Moderate DKA & $74(19.1 \%)$ \\
\hline Severe DKA & $21(5.4 \%)$ \\
\hline Frequency of ketone rebound & \\
\hline no rebound ketone & $310(80.1 \%)$ \\
\hline One times & $68(17.6 \%)$ \\
\hline two times & $6(1.6 \%)$ \\
\hline three times & $1(0.3 \%)$ \\
\hline four times & $1(0.3 \%)$ \\
\hline five times & $1(0.3 \%)$ \\
\hline Ketone free time (mean hours) & Frequency $(\%)$ \\
\hline The first ketone free time after admission (mean hours) & $9.23( \pm 10.954)$ \\
\hline The last ketone free time after admission (mean hours) & $9.49( \pm 11.051)$ \\
\hline
\end{tabular}

\subsection{The level of glycemic control of DKA patients}

The mean plasma glucose at admission and discharge was $443.63( \pm 103.33)$ and $172.94( \pm 80.60)$ $\mathrm{mg} / \mathrm{dl}$, respectively. The mean frequency of serum glycemic rebound was $6.78( \pm 4.43)$ times ranging from 0 to 32 times. The mean time at which first euglycemic state attended was 1.89( \pm 1.36$)$ (range 1-11) days and last euglycemic state attended was 4.37( \pm 2.68 ) (range 1-11) days. Larger glucose rebound value (mean) was $263.86( \pm 123.20)$ and smaller rebound value (mean) was $39.67( \pm 57.31)$. Nearly threefourth $(72.1 \%)$ of patients attended euglycemic state within fifth day. About $60 \%$ of the patients discharged with the serum glucose within the normal range and 127(32.8\%) patients were discharged with serum glucose above the normal level (hyperglycemia). No hypoglycemic episode was observed during treatment in $317(81.90 \%)$ patients and one episode of hypoglycemia was observed in $47(12.1 \%)$ patients (Table 4).

Table 4: Plasma glucose at admission, discharge and hypoglycemic episode in DKA patients at DGH from June 1 to 30, 2018. 


\begin{tabular}{|c|c|}
\hline Glucose level at admission, during Hospital stay and discharge & Frequency (\%) \\
\hline Mean RBS at admission & $443.63( \pm 103.33)$ \\
\hline Mean serum glucose at discharge & $172.94( \pm 80.60)$ \\
\hline Mean number of times serum glycemic rebound & $6.78( \pm 4.43)$ \\
\hline Mean day at which first euglycemic state attended(day) & $1.89( \pm 1.36)$ \\
\hline Mean day at which last euglycemic state attended & $4.37( \pm 2.68)$ \\
\hline Large glucose value after rebound (mean) & $263.86( \pm 123.20)$ \\
\hline Smaller glucose level after rebound (mean) & $39.67( \pm 57.31)$ \\
\hline Mean time for plasma glucose less than $250 \mathrm{mg} / \mathrm{dl}$ & $11.08( \pm 15.121)$ \\
\hline No of patients having plasma glucose $₫ 250 \mathrm{mg} / \mathrm{dl}$ within $6 \mathrm{hrs}$ & $186(48.06 \%)$ \\
\hline No of patients having plasma glucose $>250 \mathrm{mg} / \mathrm{dl}$ within $6 \mathrm{hrs}$ & $201(51.93 \%)$ \\
\hline \multicolumn{2}{|l|}{ Glycemic level at discharge } \\
\hline Hyperglycemia & $127(32.80)$ \\
\hline Euglycemic & $239(61.80)$ \\
\hline Hypoglycemia & $21(5.40)$ \\
\hline \multicolumn{2}{|l|}{ Episodes of hypoglycemia during treatment } \\
\hline 0 & $317(81.90)$ \\
\hline 1 & $47(12.10)$ \\
\hline 2 & $11(2.80)$ \\
\hline 3 & $10(2.60)$ \\
\hline 5 & $1(0.30)$ \\
\hline 8 & $1(0.30)$ \\
\hline
\end{tabular}

\subsection{Determinants of glycemic control among DKA patients}

Good glycemic control was observed in $239(61.76 \%)$ of patients. Different factors have been considered that affect the level of glycemic control. These factors include; age, gender, residence, type of DM, history of DM, duration of DM and systolic and diastolic blood pressure, severity of DKA, serum glucose level at discharge. On bivariate analysis, only two variables namely; the level of serum glucose at discharge and the duration of the disease were found to have significant association with glycemic control. A binary 
logistic regression analysis revealed that only long-standing DM was found to be associated with good glycemic control among DKA patients. It was found that for every increase in the duration of the diseases by 1 month the likelihood of controlling hyperglycemia increases nearly 1.5 times AOR:1.497[1.203-1.814] (table 5).

Table 5: Factors associated with glycemic control among DM patients attending DGH,2018

\begin{tabular}{|c|c|c|c|c|}
\hline \multirow[t]{2}{*}{ Factors } & \multicolumn{2}{|c|}{ Glycemic control } & \multirow[t]{2}{*}{ COR $95 \% \mathrm{Cl}$} & \multirow[t]{2}{*}{ AOR95\%Cl } \\
\hline & $\begin{array}{l}\text { Good } \\
239(61.75)\end{array}$ & $\begin{array}{l}\text { Poor } \\
148(38.25)\end{array}$ & & \\
\hline $\begin{array}{l}\text { Serum glucose at discharge } \\
(\mathrm{mg} / \mathrm{dl})\end{array}$ & 130.95 & 240.74 & $\begin{array}{l}0.954(0.949- \\
0.970) *\end{array}$ & $\begin{array}{l}0.974(0.969- \\
1.041)\end{array}$ \\
\hline $\begin{array}{l}\text { Duration of DM } \\
\text { (months) }\end{array}$ & 28.51 & 22.51 & $\begin{array}{l}1.496[1.303- \\
1.612]\end{array}$ & $\begin{array}{l}1.497[1.203- \\
1.814] *\end{array}$ \\
\hline
\end{tabular}

AOR: adjusted odds ratio, COR: crude odds ratio, Cl: confidence interval, * significant at 0.05 level Kaplan Meir analysis indicated that the glycemic control decreases sooner among type 1 cases when patients are followed for a duration of hospital stay, [Log rank=3.15, p-value=0.03] (figure 2).

\section{Discussion}

Our study showed that the most common clinical presentation was polyuria and polydipsia in $97.9 \%$ of patients. This result was in line with the result of cross-sectional study done in Benghazi-Libya (13) (21). The same result was found in a research done in Nigeria (22).On the contrary abdominal pain appeared to be the most common presenting symptoms in a cross-sectional study conducted in Egypt (17) and vomiting was the major clinical presentation in a research done at Saudi Arabia (12). Nausea was the most common presentation in a study done in India (2015) (23)and Bangladesh (24). The frequent occurrence of the aforementioned symptoms in DKA patients could be due to the fact that the presence of insulin deficiency results in hyperglycemia which in turn causes an osmotic diuresis. Consequently, the diuresis results in polyuria and polydipsia(25).

The most common precipitating factors were new onset type 1 DM 150(38.8\%) followed by poor compliance to antidiabetic treatment in 57(14.7\%), and infections were seen in 51(13.2\%) cases this is in line with research done in sub-Saharan Africa in which the main causes or precipitants of DKA were new onset diabetes, missed insulin doses and infections (26). On the other hand missed insulin dose was the most common PF in a cross-sectional study done in Zambia (27), cohort study done in Saudi Arabia (2015)(12), cross-sectional study Benghazi-Libya (2007)(13). other studies done in Nairobi(11), New Zealand (14), Brazil (15), and Israel reported the same finding(16). 
Infection was also found to be the frequent reason for the incidence of DKA in different studies. For instance, a research done in Jimma (10), Egypt (17) India (2015) (23), India (2009)(28), Pakistan (29), South Africa (30)and Bangladesh (31) revealed that infection was the major precipitant of DKA. Our finding also showed that urinary tract infection 24(47.05\%) was the most common infection that precipitated DKA and our result was supported with a research evidence obtained in Jimma (10), Zambia (27), India 2011 (8), India (2009)(28), Pakistan (29), Egypt (17). On the other hand respiratory tract infections was the predominant infection that precipitated DKA in a cross-sectional study done in Libya (2007) (13),and Kenya (11). As of the reason for the occurrence of frequent urinary tract infections, it can be explained that female patients took the large proportion of our sample population in whom urinary tract infection remain the most common infection(32). Overall, infectious diseases are more frequent and serious in patients with DM. Since the greater frequency of infections in diabetic patients is caused by the hyperglycemic environment that favors immune dysfunction and decrease in the antibacterial activity of urine (33).Residing in developing country where hygiene is a significant issue, attention should be sought on DM patients to keep their personal hygiene and to ultimately prevent infection.

The current study revealed that new onset type $1 \mathrm{DM}$ was the major precipitating factor of DKA. this could be due to the fact that our sample population constituted large number of type 1 DM patients in which majority of them presented with first incidence of the disease with cardinal DKA symptoms due to absolute insulin deficiency unlike type 2 DM patients(34). Although our study showed that newly diagnosed DM was the major precipitating factor for DKA, both drug non adherence and infection contributed much. The reason for non-adherence may be due to scarcity of the antidiabetic medications or lack of awareness on how to use the drugs(35). Therefore, it should be highlighted that medications with the lowest possible price should be availed. Again, awareness should also be created on diabetic self-management and the importance of adherence in preventing the occurrence of diabetic complications.

This study further illustrated glycemic control of patients with DKA who were admitted to the inpatient ward of DGH. It was found that mean time at which plasma glucose lowers below $250 \mathrm{mg} / \mathrm{dl}$ was nearly 11 hours. The reason for this long duration of time requirement for the attainment of euglycemic state was a frequent serum glucose rebound. In our study patients had a mean serum glucose rebound of around 7 times in which the patients' serum glucose increased by a maximum $263 \mathrm{mg} / \mathrm{dl}$ and a minimum of $40 \mathrm{mg} / \mathrm{dl}$ from the baseline. Correcting this fluctuation of serum glucose takes time to obtain euglycemic state sooner because successful treatment of DKA requires a prompt correction of hyperglycemia $(7,36,37)$ and the mainstay of treatment of hyperglycemia involves the administration of regular insulin via continuous intravenous infusion or by frequent subcutaneous or intramuscular injections. This ultimately helps to lower the blood glucose below $250 \mathrm{mg} / \mathrm{dl}$ within 6 hours of initiation of treatment $(7,38,39)$. The current study was the first in its kind that assessed PFs and glycemic control of DKA patients admitted in DGH. In general, the present study provided an imperative finding regarding PFS and glycemic control among DKA patients. However, this study also had few limitations. Firstly, it was a retrospective review of records performed at one hospital that is difficult to generalize. The 
retrospective nature of the study did not show causality between factors and the dependent variable. A prospective evaluation of DKA management and the PFs is required in the future perspective.

\section{Conclusions}

In this study, new onset type 1 DM was the major precipitating factor for DKA. Polyuria and polydipsia were the most common presenting clinical characteristic of DKA. Glycemic control among DKA patients was found to be unsatisfactory. Long standing DM was found to be associated with good glycemic control among DKA patients. Since, in our study most patients had poly symptoms at presentation, this could lead to dehydration and electrolyte imbalance. Therefore, strong measure should be devised in order to correct dehydration. Early detection of DKA should be sought while patients come up with poly symptoms as the symptoms are strongly related with the diagnosis of DKA. Inconsistent serum glucose level demonstrates the urgent administration of appropriate dose of regular insulin as soon as patients are diagnosed for DKA.

\section{Abbreviations}

DGH: Debre-tabor General Hospital

DKA: Diabetic Keto-Acidosis

DM: diabetes Mellitus

SD: Standard Deviation

SPSS: Statistical Manual for Social Sciences

USA: United States of America

\section{Declarations}

\section{Ethical approval}

This study was approved by University of Gondar, college of medicine and health sciences ethical approval committee with reference number 113/UoG/2018. Permission was obtained from Debre Tabor General Hospital. Informed written consent was received from participants.

\section{Consent for publication}

Not applicable

\section{Availability of data}




\section{Conflict of interest}

The authors declared no conflict of interest

\section{Funding}

No fund was received

\section{Authors' contribution}

Both authors contributed equally for the research

\section{Acknowledgments}

The author would like to acknowledge university of Gondar and Debre Tabor General Hospital for the overall support.

\section{References}

1.Chaudhury A, Duvoor C, Dendi R, Sena V, Kraleti S, Chada A, et al. Clinical review of antidiabetic drugs: Implications for type 2 diabetes mellitus management. Frontiers in endocrinology. 2017;8:6.

2.Association AD. Physical activity/exercise and diabetes mellitus. Diabetes care. 2003;26(suppl 1):s73s7.

3.Fiseha T, Alemayehu E, Kassahun W, Adamu A, Gebreweld A. Factors associated with glycemic control among diabetic adult out-patients in Northeast Ethiopia. BMC research notes. 2018;11(1):316.

4.Barski L, Nevzorov R, Rabaev E, Jotkowitz A, Harman-Boehm I, Zektser M, et al. Diabetic ketoacidosis: clinical characteristics, precipitating factors and outcomes of care. IMAJ-Israel Medical Association Journal. 2012;14(5):299.

5.Laffel L. Ketone bodies: a review of physiology, pathophysiology and application of monitoring to diabetes. Diabetes/metabolism research and reviews. 1999;15(6):412-26.

6.Association AD. Hyperglycemic crises in diabetes. Diabetes Care. 2004;27(suppl 1):s94-s102.

7.Kitabchi AE, Umpierrez GE, Miles JM, Fisher JN. Hyperglycemic crises in adult patients with diabetes. Diabetes care. 2009;32(7):1335-43. 
8.Rao V, Pradhan B, Mallikarjuna Y, Reddy R. Clinical profile of diabetic ketoacidosis in adults. Health Renaissance.10(2):80-6.

9.Maskey R, Shakya DR, Nikesh B, Krishna KA, Lavaju P, Kattel V, et al. Clinical profile of diabetic ketoacidosis in tertiary care hospital of Eastern Nepal. Indian journal of endocrinology and metabolism.19(5):673.

10.Desse TA, Eshetie TC, Gudina EK. Predictors and treatment outcome of hyperglycemic emergencies at Jimma University Specialized Hospital, southwest Ethiopia. BMC research notes.8(1):553.

11.Mbugua P, Otieno C, Kayima J, Amayo A, McLigeyo S. Diabetic ketoacidosis: clinical presentation and precipitating factors at Kenyatta National Hospital, Nairobi. East African medical journal. 2005;82(12).

12.Almalki MH, Buhary BM, Khan SA, Almaghamsi A, Alshahrani F. Clinical and Biochemical Characteristics of Diabetes Ketoacidosis in a Tertiary Hospital in Riyadh. Clinical Medicine Insights: Endocrinology and Diabetes.9:CMED. S39639.

13.Elmehdawi RR, Ehmida M, Elmagrehi $\mathrm{H}$, Alaysh A. Incidence and mortality of diabetic ketoacidosis in Benghazi-Libya in 2007. Oman medical journal.28(3):178.

14.Yong KW, Moore MP, Lunt $\mathrm{H}$. Medically facilitated discharge of adult diabetic ketoacidosis admissions: precipitants and average length of stay. NZ Med J.127:86-94.

15.Weinert LS, Scheffel RS, Severo MD, Cioffı AP, Tel $\tilde{A}^{3}$ GH, Boschi A, et al. Precipitating factors of diabetic ketoacidosis at a public hospital in a middle-income country. Diabetes research and clinical practice.96(1):29-34.

16.Barski L, Nevzorov R, Rabaev E, Jotkowitz A, Harman-Boehm I, Zektser M, et al. Diabetic ketoacidosis: clinical characteristics, precipitating factors and outcomes of care. IMAJ-Israel Medical Association Journal.14(5):299.

17.Zeinab Shafeek Shafeek Hamed, Amr Mohamed Gawaly, Khalil Mohamed Abbas, Ahwal LME. Epidemiology of infection as a precipitating factor for diabetic ketoacidosis at Tanta University Hospital. Tanta Medical Journal. 2017;45:68-72.

18.Moghissi ES, Korytkowski MT, DiNardo M, Einhorn D, Hellman R, Hirsch IB, et al. American Association of Clinical Endocrinologists and American Diabetes Association consensus statement on inpatient glycemic control. Diabetes care. 2009;32(6):1119-31.

19.Association AD. Glycemic targets: standards of medical care in diabetes-2018. Diabetes Care. 2018;41(Supplement 1):S55-S64.

20.Whelton PK, Carey RM, Aronow WS, Casey DE, Collins KJ, Himmelfarb CD, et al. 2017 ACC/AHA/AAPA/ABC/ACPM/AGS/APhA/ASH/ASPC/NMA/PCNA guideline for the prevention, detection, 
evaluation, and management of high blood pressure in adults: a report of the American College of Cardiology/American Heart Association Task Force on Clinical Practice Guidelines. Journal of the American College of Cardiology. 2018;71(19):e127-e248.

21.Elmehdawi R, Elmagerhei H. Profile of diabetic ketoacidosis at a teaching hospital in Benghazi, Libyan Arab Jamahiriya. Eastern Mediterranean Health Journal 2010;16(3).

22.Edo AE. Clinical profile and outcomes of adult patients with hyperglycemic emergencies managed at a tertiary care hospital in Nigeria. Nigerian medical journal: journal of the Nigeria Medical Association.53(3):121.

23. Hartalkar A, Hartalkar S, Peshwe K, Nath B. Profile of precipitating factors in diabetic ketoacidosis: data from a rural teaching hospital. Insulin.30:75.

24.Rahim MA, Rouf R, Ahmed AU, Mitra P, Zaman S, Uddin KN, et al. Clinical Characteristics and Outcome of Diabetic Ketoacidosis: Experience at BIRDEM, Dhaka, Bangladesh. Bangladesh Critical Care Journal.3(2):53-6.

25.Tripathy B, Chandalia HB, Das AK. RSSDI textbook of diabetes mellitus: JP Medical Ltd.

26.Otieno C, Kayima J, Omonge E, Oyoo G. Diabetic ketoacidosis: risk factors, mechanisms and management strategies in sub-Saharan Africa: a review. East African medical journal. 2005;82(12).

27.Kakusa M, Kamanga B, Ngalamika O, Nyirenda S. Comatose and noncomatose adult diabetic ketoacidosis patients at the University Teaching Hospital, Zambia: Clinical profiles, risk factors, and mortality outcomes. Indian journal of endocrinology and metabolism.20(2):199.

28.Mahesh M, ShlvaSwaMy RP, ChandRa BS, Syed S. The Study of Different Clinical Pattern of Diabetic Ketoacidosis and Common Precipitating Events and Independent Mortality Factors. Journal of clinical and diagnostic research: JCDR.11(4):OC42.

29.Jabbar A, Farooqui K, Habib A, Islam N, Haque N, Akhter J. Clinical characteristics and outcomes of diabetic ketoacidosis in Pakistani adults with Type 2 diabetes mellitus. Diabetic medicine. 2004;21(8):920-3.

30.Ndebele NF, Naidoo M. The management of diabetic ketoacidosis at a rural regional hospital in KwaZulu-Natal. African journal of primary health care \& family medicine. 2018;10(1):1-6.

31.Ahmed AU, Rahim MA, Rahman MR, Nazim RF, Uddin KN. Diabetic ketoacidosis: Pattern of precipitating causes. J Enam Med Coll.4(2):94-7.

32.Patterson JE, Andriole VT. Bacterial urinary tract infections in diabetes. Infectious Disease Clinics. 1997;11(3):735-50. 
33.Casqueiro J, Casqueiro J, Alves C. Infections in patients with diabetes mellitus: A review of pathogenesis. Indian journal of endocrinology and metabolism.16(Suppl1):S27.

34.Atkinson MA. The pathogenesis and natural history of type 1 diabetes. Cold Spring Harbor perspectives in medicine. 2012;2(11):a007641.

35.Kalogianni A. Factors affect in patient adherence to medication regimen. Health Science Journal. 2011;5(3):157.

36.Goguen J, Gilbert J. Hyperglycemic emergencies in adults. Canadian journal of diabetes.37:S72-S6.

37.Yehia BR, Epps KC, Golden SH. Diagnosis and management of diabetic ketoacidosis in adults. Hospital Physician. 2008;35:21-6.

38.Umpierrez GE, Kelly JP, Navarrete JE, Casals MM, Kitabchi AE. Hyperglycemic crises in urban blacks. Archives of internal medicine. 1997;157(6):669-75.

39.Umpierrez GE, Jones S, Smiley D, Mulligan P, Keyler T, Temponi A, et al. Insulin analogs versus human insulin in the treatment of patients with diabetic ketoacidosis: a randomized controlled trial. Diabetes care. 2009.

\section{Figures}

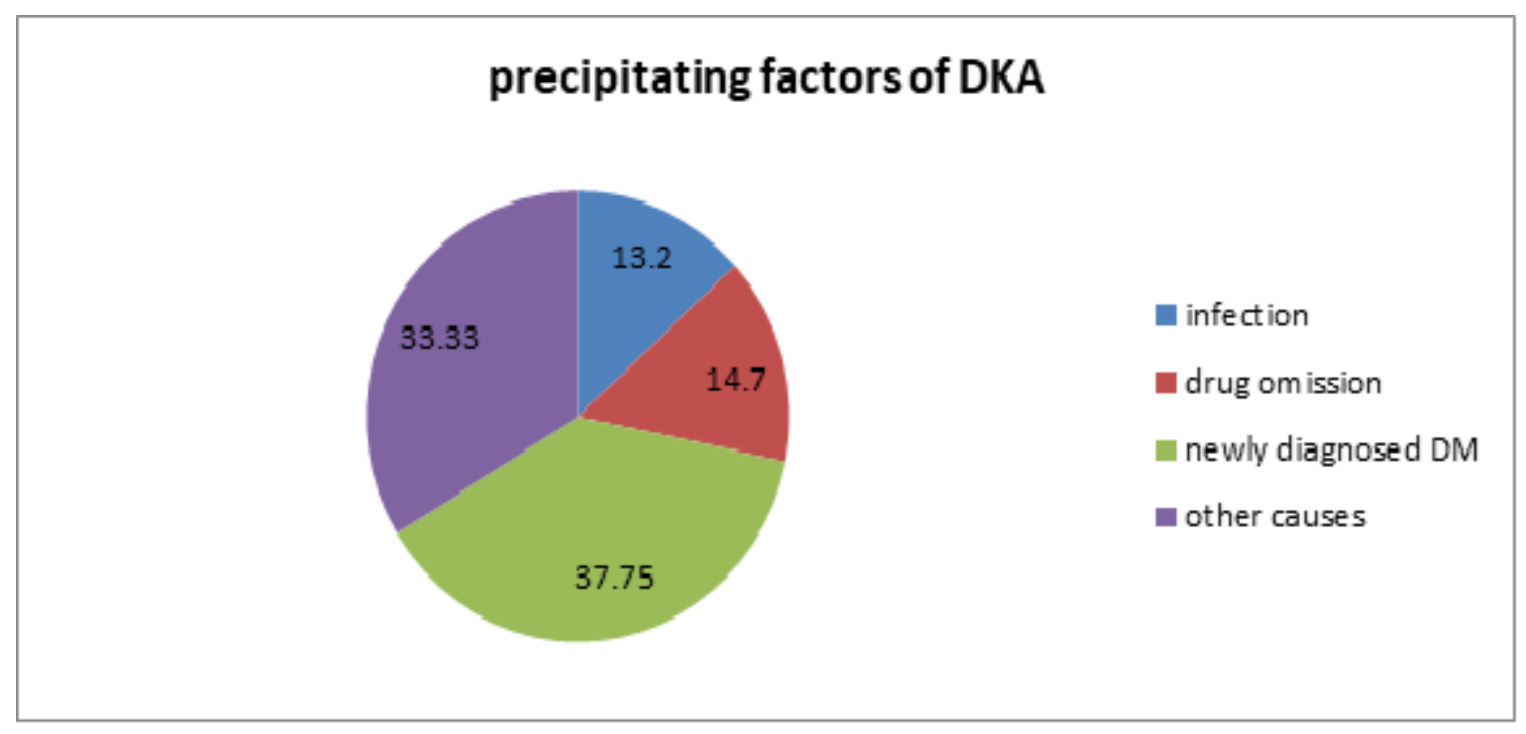

\section{Figure 1}

Precipitating factors for DKA among DM patients attending DGH, 2018. 


\section{Survival Functions}

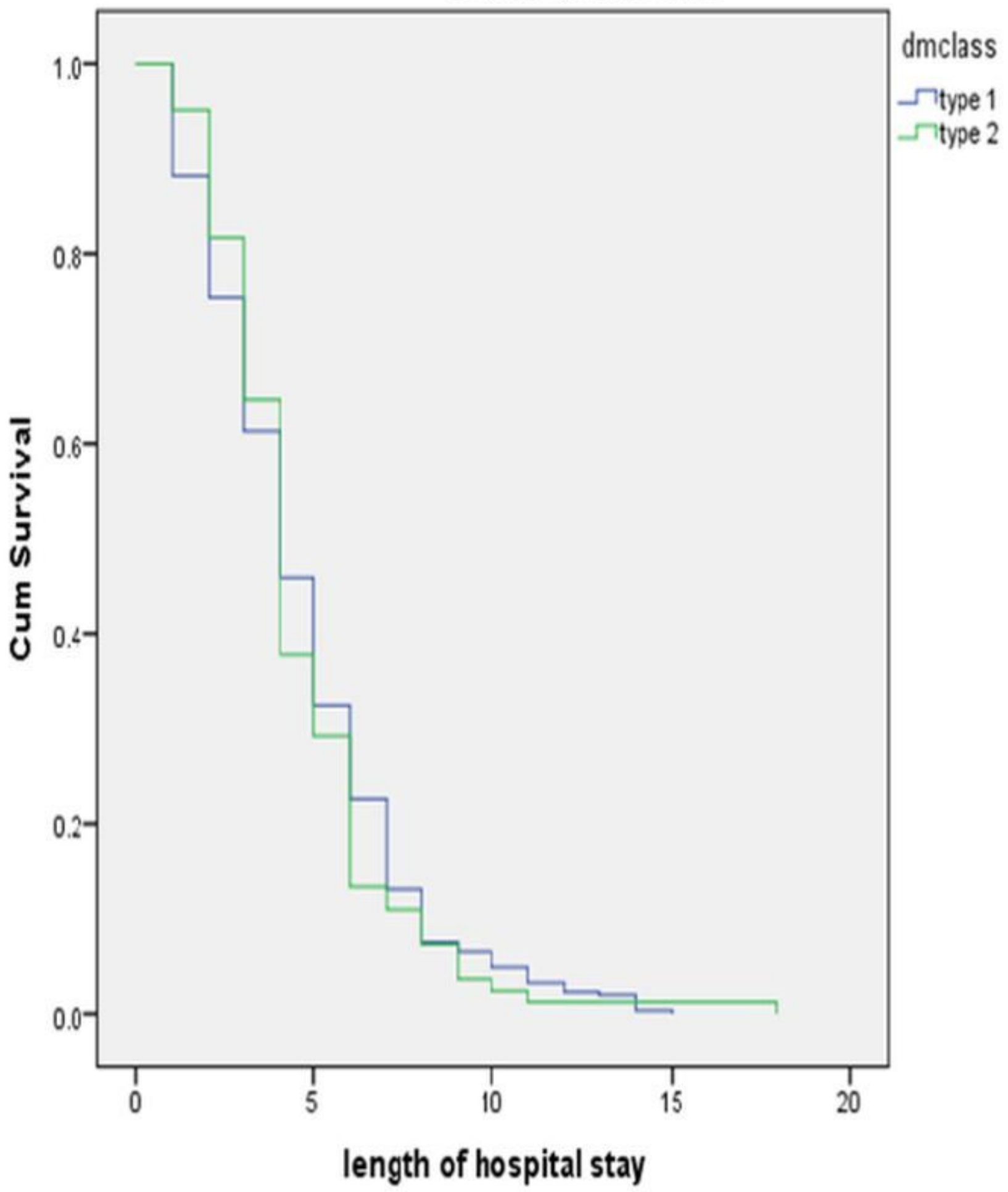

Figure 2

Precipitating factors for DKA among DM patients attending DGH, 2018. 